\title{
Kinin-Forming Enzyme in Rat Brain Mitochondria Fraction and Biological Activity of a Kinin Released from Rat Plasma Kininogen by This Enzyme
}

\author{
Kimio KARIYA, Hiroshi OKAMOTO and Kazuya KIRA \\ Department of Pharmacology. Faculty of Pharmaceutical Sciences, \\ Kobe-Gakuin University, Ikawadani-cho, Nishi-ku, Kobe 673, Japan
}

Accepted October 4, 1983

\begin{abstract}
The kinin-forming enzyme of rat brain was studied by bioassaying kinin using a rat uterus. This enzyme released a kinin from the partially purified kininogen of rat plasma. The activity is exclusively distributed in the mitochondrial fraction and was detected in the $\mathrm{pH}$ range of 2.5-4.0 (optimally at $\mathrm{pH} 3.0$ ). The enzyme was potently inhibited by pepstatin, but not by aprotinin. Released kinin was extracted by n-butanol and it was purified using Amberlite CG-50 absorption and CMcellulose column chromatography. The elution profile of kinin from the CMcellulose column did not coincide with that of bradykinin, Lys-bradykinin or Met-Lysbradykinin. Isolated kinin was inactivated by treatment with chymotrypsin, but not with trypsin. In addition to the contractile activity on rat uterus, the kinin caused contraction of guinea pig ileum, with the response being potentiated by the presence of bradykinin-potentiator B. It also relaxed a rat duodenum, decreased rat blood pressure, and increased the vascular permeability in guinea pigs. Relative potencies of kinin on these pharmacological activities did not coincide with those of bradykinin. From these results, it is concluded that a kinin-forming enzyme is present in the rat brain. It is a cathepsin D-like enzyme, and furthermore, the enzyme releases a kinin-like peptide from the plasma kininogen fraction.
\end{abstract}

Many physiologically active peptides located in the peripheral tissues such as substance $P$, neurotensin, cholecystokinin and vasoactive intestinal polypeptide have been demonstrated in the brain or nervous tissues (1-4). However, evidence regarding the presence of kinin has never been reported, until a recent paper demonstrated the presence of a bradykinin-like immunoreactive substance in the rat brain by Corréa et al. (5). Extensive work has been done on the kallikrein-kinin system in peripheral tissues; however, very little is known about its role in the brain. Among components reported are a kallikrein-like enzyme $(6,7)$, a kininogenlike substance $(7,8)$ and kininase $(9,10)$ in the brain; kallikrein-like activity has been reported in the microsomal fraction of the rabbit brain, but its activity was detected only by the pretreatment with acetone or acid (6). In the rat brain, the formation of activity corresponding to a kinin-like substance was observed in the acidic $\mathrm{pH}$ range using bioassay (7). The evidence showing the possibility for the presence of a kininforming enzyme in the brain, however, was uncertain as to whether the substance causing contraction of the isolated smooth muscle was kinin under the experimental conditions employed.

In the present paper, we studied the kininforming activity in rat brain by using partially purified kininogen from rat plasma as the substrate.

\section{Materials}

\section{Materials and Methods}

DEAE-Sephadex A-50 was from Pharmacia Fine Chemicals (Uppsala, Sweden). CM-cellulose from Nakarai Chemicals 
(Kyoto, Japan), and Amberlite CG-50 resin from Organo Company (Tokyo, Japan). Bradykinin, Lys- and Met-Lys-bradykinin. bradykinin potentiator $B$ and pepstatin were purchased from the Protein Research Foundation (Osaka, Japan). Trypsin (bovine pancreas, type III), chymotrypsin (bovine pancreas, Type (I), soybean trypsin inhibitor. diisopropylfluorophosphate (DFP) and phenylmethyl sulfonylfluoride (PMSF) were obtained from Sigma Chemical Company (U.S.A.). Aprotinin was a gift from Hoechst Japan, and highly purified porcine pancreatic kallikrein was kindly supplied by Bayer Yakuhin Ltd. (Japan).

\section{Bioassay of kinin}

An isolated rat uterus preparation was used for assays of kininogen concentration or kinin-forming activity. Virgin rats weighing 180-250 g were injected s.c. with $0.2 \mathrm{mg} / \mathrm{kg}$ of estradiol benzoate (Teikoku Zoki, Tokyo, Japan) $16 \mathrm{hr}$ before assay. The isolated uterus was suspended at $28^{\circ} \mathrm{C}$ in a $10 \mathrm{ml}$ siliconized organ bath filled with de Jalon's solution containing $2 \mu \mathrm{M}$ atropine and $4 \mu \mathrm{M}$ diphenhydramine gassed with air. Contractile responses were measured isotonically for 90 $\mathrm{sec}$ at $2 \mathrm{~min}$ intervals. Synthetic bradykinin was used as the standard.

Preparation of kininogen fraction from rat plasma

Partially purified kininogen was obtained from rat plasma according to the procedure of Li et al. (11). The preparation was dialyzed against $0.15 \mathrm{M} \mathrm{NaCl}$, and the content was 0.84 nmole bradykinin equiv./mg protein.

\section{Enzyme preparation from rat brain}

Male Sprague-Dawley rats, weighing 200$350 \mathrm{~g}$, were anesthetized with pentobarbital $\mathrm{Na}$ (30 mg/ $/ \mathrm{kg}$, i.p.), and the infusion of cold saline, through a cannula inserted in each carotid artery, was completed for removal of blood from the brain. After exsanguinating from the jugular veins, the whole brain was removed. The tissue was homogenized with 9 vol. of $0.32 \mathrm{M}$ sucrose (buffered with 10 $\mathrm{mM}$ Tris- $\mathrm{HCl}, \mathrm{pH}$ 7.0), with subcellular fractionation being carried out according to the procedure of Koenig et al. (12). The homogenate was centrifuged at $800 \mathrm{~g}$ for $10 \mathrm{~min}$ to separate the fraction containg nuclei and unbroken cells. The supernatant fluid was centrifuged at $15,700 \mathrm{~g}$ for $20 \mathrm{~min}$. and the pellet, the crude mitochondrial fraction, was washed once with the sucrose solution. The combined supernatant was centrifuged at $100,000 \mathrm{~g}$ for $60 \mathrm{~min}$. The pellet was designated as the microsomal fraction. The pellets were suspended in an appropriate volume of $0.15 \mathrm{M} \mathrm{NaCl}$, and the soluble supernatant was dialyzed against $0.15 \mathrm{M} \mathrm{NaCl}$.

\section{Assay of kinin-forming activity}

Kinin-formation was detected by bioassay using a rat uterus. Incubation was carried out in $250 \mu l$ of $50 \mathrm{mM}$ glycine- $\mathrm{HCl}$ buffer $(\mathrm{pH}$ 3.0) containing $0.5 \mathrm{mM}$ EDTA, $0.24 \mathrm{mg}$ protein of the kininogen preparation, and 0.05-0.4 mg protein from the enzyme preparations, using siliconized tubes at $37^{\circ} \mathrm{C}$. After incubating for $1 \mathrm{hr}$, the mixture was chilled in ice, and the formed kinin was assayed using the rat uterus.

For comparison, the kinin-forming activity of purified porcine pancreatic kallikrein was determined, using partially purified beef plasma kininogen as a substrate, according to the method of Moriwaki et al. (13).

Extraction and purification of kinin from the incubation mixture

Isolation of kinin from the reaction mixture was performed using the procedure of bradykinin extraction (14).

1. Reaction and $n$-butanol extraction: The reaction mixture contained $60 \mathrm{mg}$ protein of the crude mitochondria of rat brain, $36 \mathrm{mg}$ protein of partially purified plasma kininogen, $0.5 \mathrm{mM}$ EDTA and $50 \mathrm{mM}$ glycine- $\mathrm{HCl}$ buffer ( $\mathrm{pH} 3.0$ ) in a total volume of $37.5 \mathrm{ml}$. When the amount of kinin attained a plateau after incubation for $6 \mathrm{hr}$ at $37^{\circ} \mathrm{C}$, the reaction was terminated by adjusting the $\mathrm{pH}$ to 2.0 with $1.0 \mathrm{~N} \mathrm{HCl}$.

This mixture was saturated with $\mathrm{NaCl}$, and the solution was shaken twice with 60 $\mathrm{ml}$ of $\mathrm{n}$-butanol. The butanol phases were combined, and $30 \mathrm{~g}$ of anhydrous sodium sulfate was added to eliminate the water. The suspension was agitated for $15 \mathrm{~min}$ and stored overnight at $-20^{\circ} \mathrm{C}$. After the organic phase was separated by centrifugation, $12 \mathrm{ml}$ of ethylether was added. The solution was agitated for $5 \mathrm{~min}$ with $12 \mathrm{ml}$ distilled water. and extraction was repeated. The combined 
aqueous phase was lyophilized.

2. Amberlite CG-50 absorption: The Iyophilizate was dissolved in $10 \mathrm{ml}$ distilled water, and $3 \mathrm{~g}$ of Amberlite CG -50 resin (100200 mesh, $\mathrm{H}^{+}$-form) was added. The $\mathrm{pH}$ was adjusted to 4.0 with $0.5 \mathrm{~N} \mathrm{NaOH}$, and gentle stirring was continued for $10 \mathrm{~min}$. The mixture was centrifuged, and the resin was washed three times with $20 \mathrm{ml}$ distilled water. Kinin was eluted by shaking twice with $10 \mathrm{ml}$ of $50 \%$ acetic acid. The elute was lyophilized.

3. CM-cellulose chromatography: The lyophilizate was dissolved in $5 \mathrm{ml}$ of $0.01 \mathrm{M}$ ammonium formate ( $\mathrm{pH} 5.0$ ), and the solution was applied to a column of CM-cellulose $(0.6 \times 20 \mathrm{~cm})$ previously equilibrated with $0.01 \mathrm{M}$ ammonium formate $(\mathrm{pH} 5.0)$ containing $1.0 \mathrm{mM}$ EDTA. The column was washed with $30 \mathrm{ml}$ of the buffer, and then the elution was performed with a linear-gradient of the buffer $(100 \mathrm{ml})$ against $0.5 \mathrm{M} \mathrm{am}$ monium formate ( $\mathrm{pH} 7.5$ ) containing $1.0 \mathrm{mM}$ EDTA $(100 \mathrm{ml}$ ) (flow rate $20 \mathrm{ml} / \mathrm{hr}, 3 \mathrm{ml}$ / fraction). Kinin activity in the elute was measured using the rat uterus.

\section{Protein determination}

Protein was determined by the modified Lowry procedure (15) with bovine serum albumin as the standard.

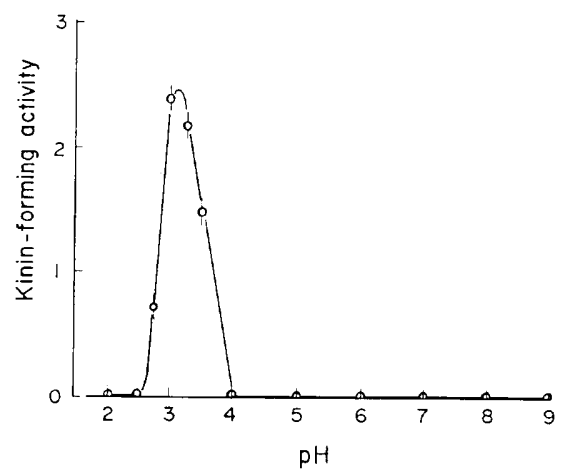

Fig. 1. Influence of $\mathrm{pH}$ on the kinin-forming activity of the crude mitochondrial fraction in rat brains. Points and vertical bars represent means \pm S.D. for four experiments, expressed as pmoles bradykinin equiv./mg protein/min. Each $50 \mathrm{mM}$ buffer was adjusted to yield the following $\mathrm{pH}$ in the presence of $0.5 \mathrm{mM}$ EDTA: glycine- $\mathrm{HCl}$ (2.0-4.0), acetate $(4.0-6.0)$, sodium phosphate $(6.0-8.0)$, Tris- $\mathrm{HCl}$ $(8.0-9.0)$.

\section{Results}

Influences of $\mathrm{pH}$ on the kinin-forming activity: Figure 1 shows the influence of $\mathrm{pH}$ on the kinin-forming activity of the crude mitochondria of the rat brain. Kinin liberation from the plasma kininogen fraction was only observed in the acidic $\mathrm{pH}$ range. optimally at $\mathrm{pH}$ 3.0. At $\mathrm{pH}$ 3.0, the kinin formation increased linearly up to $2 \mathrm{hr}$ of incubation and to a concentration of $3.0 \mathrm{mg}$ protein $/ \mathrm{ml}$ of the enzyme preparation (Fig. 2a and 2b).

Subcellular distribution of the kininforming activity at $\mathrm{pH}$ 3.0: Table 1 shows the subcellular distribution of the kinin-forming activity of the rat brain at $\mathrm{pH}$ 3.0. Specific activity was higher in the crude mitochondrial fraction than in the other fractions. More

a)

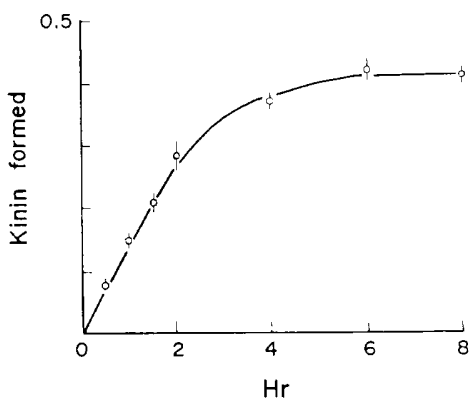

b)

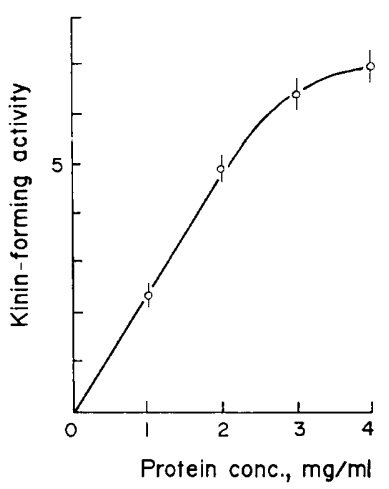

Fig. 2. Kinin-forming activities as a function of incubation time and as a function of the amount of crude mitochondrial fraction from the rat brain. a) the time course of activity; b), effect of the amount of crude mitochondrial fraction on kinin-formation. Points and vertical bars represent means \pm S.D. for four experiments, expressed as a) nmoles/mg protein and b) pmoles/min. 
than $70 \%$ of the total activity was observed in this fraction.

Effects of inhibitors: Table 2 shows the effects of various proteinase inhibitors on the kinin-forming activity in the rat brain and the purified porcine pancreatic kallikrein. The rat brain enzyme was potently inhibited by pepstatine, but porcine kallikrein was not inhibited at all. Aprotinin, which is a potent inhibitor of pancreatic kallikrein, did not affect the brain enzyme. The brain enzyme was inhibited by PMSF and DFP, but not by SBIT.

Purification of kinin from the incubation mixture and its identification: As summarized in Table 3, kinin liberated from the plasma kininogen fraction by incubating with the crude mitochondrial fraction was extracted and purified by the procedures described in Materials and Methods. The column chromatogram obtained using $\mathrm{CM}$-cellulose is illustrated in Fig. 3, in comparison to authentic bradykinin by assay with rat uterus. Kinin extracted from the incubation mixture was detected as one peak, and this eluted with a elution volume different from those of authentic bradykinin, Lys-bradykinin and MetLys-bradykinin (Fig. $3 a$ and $3 b$ ). When the

Table 1. Subcellular distribution of kinin-forming enzyme in rat brain

\begin{tabular}{lcc}
\hline Fraction & $\begin{array}{c}\text { Specific activity } \\
\text { (pmoles/mg protein/min) }\end{array}$ & $\begin{array}{c}\text { Total activity } \\
(\%)\end{array}$ \\
Whole homogenate & $1.89 \pm 0.18$ & 100 \\
Nuclei \& unbroken cells & $0.69 \pm 0.14$ & 8.9 \\
Crude mitochondria & $2.51 \pm 0.10$ & 71.4 \\
Microsomes & $0.27 \pm 0.04$ & 2.4 \\
Supernatant & $1.04 \pm 0.80$ & 8.4 \\
\hline
\end{tabular}

aValues represent means \pm S.D. as bradykinin equivalent for four experiments.

Table 2. Effects of some proteinase inhibitors on the kinin-formation by the crude mitochondrial fraction of rat brain and porcine pancreatic kallikrein

\begin{tabular}{|c|c|c|c|}
\hline \multirow{2}{*}{ Inhibitor } & \multirow{2}{*}{ Concentration } & \multicolumn{2}{|c|}{$\%$ inhibition } \\
\hline & & $\begin{array}{l}\text { Brain crude } \\
\text { mitochondriad }\end{array}$ & $\begin{array}{l}\text { Pancreatic } \\
\text { kallikreine }^{\text {e }}\end{array}$ \\
\hline \multirow[t]{3}{*}{ Pepstatin } & $2 \mathrm{nM}$ & 21 & $-\mathrm{g}$ \\
\hline & 20 & 32 & - \\
\hline & 200 & 95 & 0 \\
\hline \multirow[t]{2}{*}{ PMSFa } & $0.2 \mathrm{mM}$ & 9 & - \\
\hline & 2.0 & 37 & 0 \\
\hline \multirow[t]{3}{*}{$\mathrm{DFPb}$} & $0.1 \mathrm{mM}$ & 21 & 100 \\
\hline & 1.0 & 58 & - \\
\hline & 10.0 & 100 & - \\
\hline \multirow[t]{2}{*}{ Aprotinin } & $50 \mathrm{KIU} / \mathrm{ml}^{\mathrm{f}}$ & - & 100 \\
\hline & 500 & 0 & - \\
\hline \multirow[t]{2}{*}{ SBT|c } & $0.1 \mathrm{mg} / \mathrm{ml}$ & - & - \\
\hline & 1.0 & 0 & 0 \\
\hline
\end{tabular}

Values represent means of $\%$ inhibition for three experiments. aphenylmethyl sulfonylfluoride, bDiisopropylfluorophosphate, "Soybean trypsin inhibitor. Specific activity of control was 2.27 pmoles/ $\mathrm{mg}$ protein/min or e $680 \mathrm{nmoles} / \mathrm{mg}$ protein/min, expressed as bradykinin equivalent assayed by rat uterus. KKallikrein inhibiting units, gNot determined. Purified porcine pancreatic kallikrein was incubated at the concentration of $1 \mu \mathrm{g} / \mathrm{ml}$ with partially purified beef plasma kininogen in $50 \mathrm{mM} \mathrm{Tris-HCl}$ buffer, $\mathrm{pH} 8.0$, at $30^{\circ} \mathrm{C}$ for $1 \mathrm{~min}$. 
Table 3. Purification of kinin from the incubation mixture

\begin{tabular}{lcccc}
\hline \multicolumn{1}{c}{ Step } & $\begin{array}{c}\text { Volume } \\
(\mathrm{ml})\end{array}$ & $\begin{array}{c}\text { Concentration } \\
(\text { nmoles/ml })\end{array}$ & $\begin{array}{c}\text { Total } \\
(\mathrm{nmoles})\end{array}$ & $\begin{array}{c}\text { Yield } \\
(\%)\end{array}$ \\
\cline { 5 - 5 } Incubation mixture & 37.5 & 0.68 & 25.5 & 100 \\
Butanol extract & 10.0 & 2.53 & 25.3 & 99.2 \\
Amberlite adsorption & 5.0 & 2.82 & 14.1 & 55.3 \\
CM-cellulose chromatography & 5.0 & 2.10 & 10.5 & 41.2 \\
\hline
\end{tabular}

The amounts of kinin are expressed as bradykinin equivalent assayed by rat uterus.
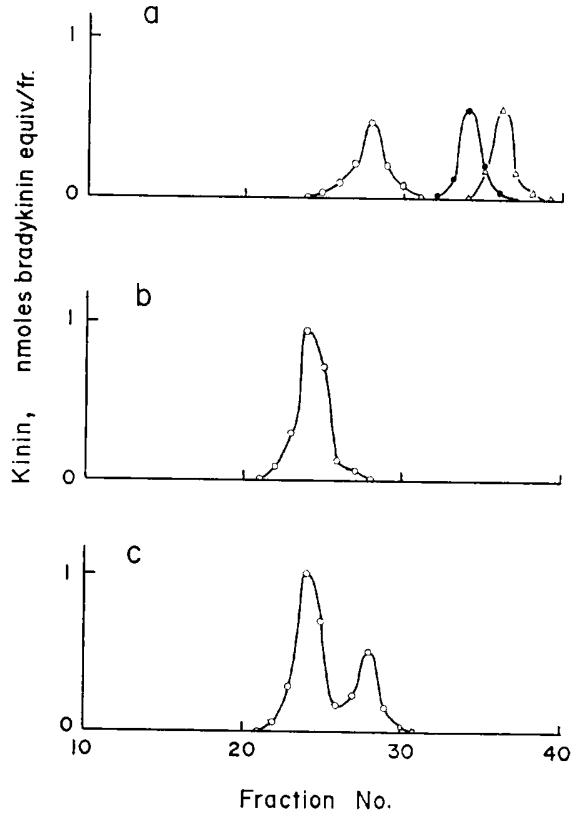

Fig. 3. CM-cellulose chromatography of extracted kinin and standard kinins. The solutions of kinins in $10 \mathrm{mM}$ ammonium formate buffer, $\mathrm{pH}$ 5.0, were applied to $\mathrm{CM}$-cellulose columns $(0.6 \times 20 \mathrm{~cm})$. Columns were washed and eluted as described in Materials and Methods. Fractions of $3 \mathrm{ml}$ were collected. a), standard kinins (each 1 nmole) were separately applied: bradykinin (-O-), Lysbradykinin $\left(-\triangle_{-}\right)$and Met-Lys-bradykinin (-) - b), extracted kinin (3.6 nmole bradykinin equivalent using a rat uterus) of Amberlite CG-50 elute. c), mixture of bradykinin (1 nmole) and extracted kinin (3.6 nmole bradykinin equivalent using a rat uterus). Fractions were assayed by using a rat uterus, expressed as nmoles bradykinin equiv./ fraction.

mixture of extract and the authentic bradykinin was applied, two peaks were detected (Fig. 3c).

Effects of trypsin and chymotrypsin

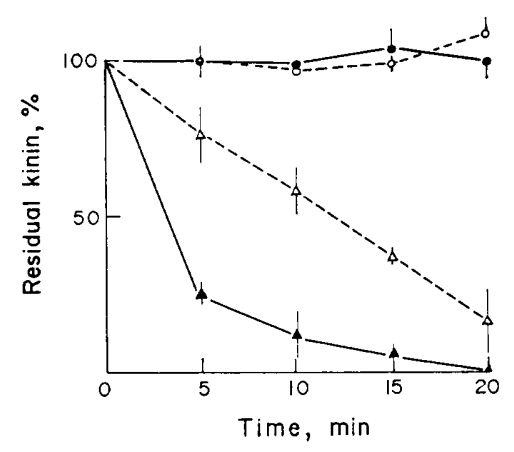

Fig. 4. Effects of trypsin and chymotrypsin degestion on the contractile activity of isolated kinin on a rat uterus. Eluted kinin from $\mathrm{CM}$-cellulose column and bradykinin were incubated with trypsin $(10 \mu \mathrm{g} / \mathrm{ml})$ or chymotrypsin $(10 \mu \mathrm{g} / \mathrm{ml})$ in $0.12 \mathrm{M}$ Tris- $\mathrm{HCl}$ buffer, at $\mathrm{pH} 7.8$, each time. Reactions were stopped by the addition of SBTl $(50 \mu \mathrm{g} / \mathrm{ml})$ for trypsin or DFP (2 $\mathrm{mM}$ ) for chymoprypsin. Residual kinins were assayed by use of a rat uterus and expressed as $\%$ of the control. Isolated kinin incubated with trypsin $(\cdots \bigcirc--)$ and chymotrypsin $(\cdots \triangle \cdots)$. Bradykinin with trypsin (-O) and chymotrypsin $(-\mathbf{\Delta}-)$. Points and vertical bars represent means \pm S.D. for three experiments.

digestion on the activity of purified kinin: Figure 4 shows the contractile activities of purified kinin eluted from the CM-cellulose column and authentic bradykinin incubated with trypsin and chymotrypsin as a function of incubation time. The contractile activity of the kinin on the rat uterus was not affected with trypsin treatment, similar to what was observed for bradykinin. By chymotrypsin treatment, the kinin was inactivated in a manner similar to bradykinin, but the inactivation rate was slower than that for bradykinin.

Biological activities of purified kinin: As shown in Fig. 5, the purified kinin con- 
A Guinea pig ileum

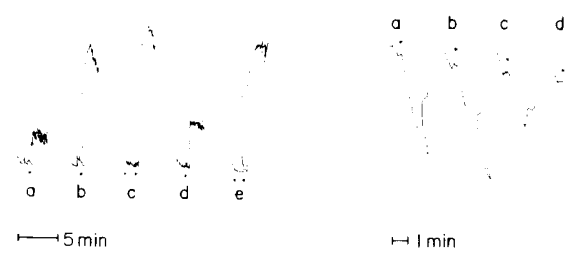

C Rat blood pressure

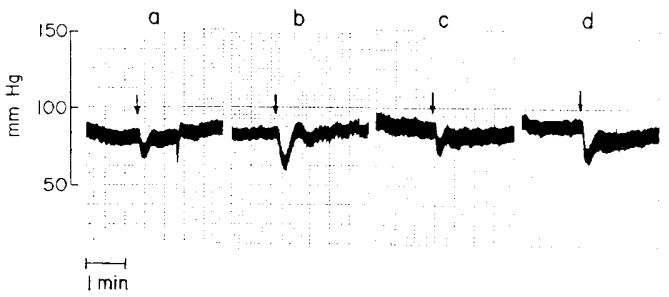

Fig. 5. Pharmacological activities of isolated kinir. The preparations of A), an isolated guinea pig ileum. and $B$ ), an isolated rat doudenum, were suspended at $28^{\circ} \mathrm{C}$ in a $10 \mathrm{ml}$ organ bath filled with Tyrode's solution containing $2 \mu \mathrm{M}$ atropine and $4 \mu \mathrm{M}$ diphenhydramine gassed with air. The response of contraction or relaxation was recorded isotonically for $2 \mathrm{~min}$. The doses of kinin were in A): a, bradykinin (5 $\mathrm{nM})$; b, bradykinin $(10 \mathrm{nM})$; c, bradykininpotentiator $\mathrm{B}(0.25 \mu \mathrm{M})$ followed by bradykinin ( 5 $\mathrm{nM})$ : d, isolated kinin $(10 \mathrm{nM})$ : e, bradykininpotentiator B $(0.25 \mu \mathrm{M})$ followed by isolated kinin $(10 \mathrm{nM})$ : and in $\mathrm{B})$ : a, bradykinin $(0.05 \mathrm{nM})$; b. bradykinin $(0.075 \mathrm{nM})$; c, isolated kinin (0.04 nM); $d$, isolated kinin $(0.08 \mathrm{nM})$. C), blood pressure of rat: a male Sprague-Dawley rat, weighing $450 \mathrm{~g}$. was anesthetized with urethane $(1.5 \mathrm{~g} / \mathrm{kg}$, i.p.), and the blood pressure was recorded at the carotid artery. Kinins were dissolved in saline and injected into the carotid vein at a volume of $50 \mu \mathrm{l}$. The doses of kinins were: bradykinin, 1.25 (a) and 2.5 (b) nmole: isolated kinin, 0.05 (c) and 0.10 (d) nmole. The amounts of isolated kinin were expressed as bradykinin equivalent assayed by a rat uterus.

tracted the guinea pig ileum preparation, relaxed the rat doudenum and depressed rat blood pressure, actions similar to those of bradykinin. Pretreatment of the guinea pig ileum with bradykinin potentiator $B$ peptide, which is known to be a decapeptide (16), increased the potential for contractile activity

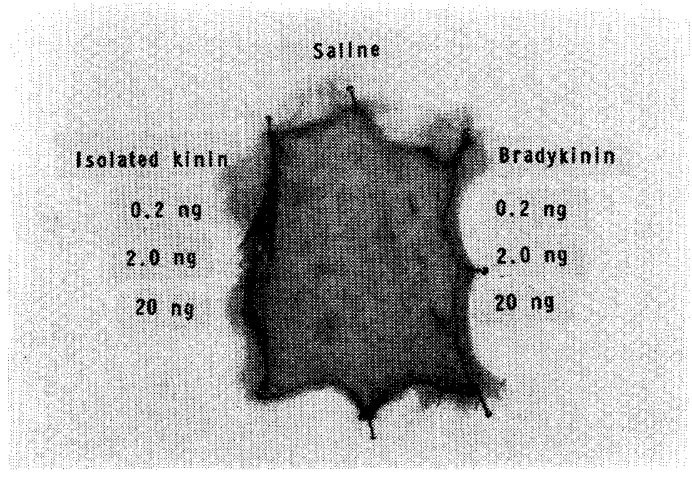

Fig. 6. Effects of isolated kinin on vascular permeability increasing activity in guinea pig. Abdominal hair of the animals ( $350 \mathrm{~g}$, male) was removed using an electric clipper before experiments. One $\mathrm{ml}$ of $0.5 \%$ Evans blue in saline was injected into the basilic vein, and then saline, isolated kinin and authentic bradykinin were administered iritracutaneously into the animals at $0.1 \mathrm{ml}$ volume. Ten minutes later, the animal was decapitated and skinned, and the blueing of the injection areas was observed visually.

by the kinin.

The permeability increasing activity of isolated kinin is presented in the photograph of Fig. 6. No blueing area was observed at the top of the center of the skin injected with saline. On the other hand, injection of isolated kinin caused visible blueing in dosedependence. The authentic bradykinin showed a little lower activity than that of purified kinin. However, when the amounts of isolated kinin were converted to the bradykinin equivalent assayed by the rat uterus, their effects seemed similar.

Table 4 summerizes the potencies of the kinin as compared to those of bradykinin. Assuming that the kinin was equipotent with bradykinin on the rat uterus, the potencies on guinea pig ileum and rat duodenum were about 3 and 1.5 times less than those of bradykinin, respectively. The potency on rat blood pressure was about 20 -fold that of bradykinin.

\section{Discussion}

In order to clarify the presence of a kininforming enzyme in the brain, the kinin formed from the kininogen fraction of rat 
Table 4. Comparison of potencies of the isolated kinin arid bradykinin

\begin{tabular}{lc}
\hline & $\begin{array}{l}\text { Relative amounts of bradykinin } \\
\text { required for the same response } \\
\text { as isolated kinin }\end{array}$ \\
Rat uterus contraction & 1 \\
Guinea pig ileum contraction & 0.32 \\
Rat duodenum relaxation & 0.77 \\
Blood pressure fall in rat & 20 \\
Vascular permeability in guinea pig & 1 \\
\hline
\end{tabular}

Values are expressed as the isolated kinin to be equipotent with bradykinin on rat uterus.

Values are means of four experiments.

plasma by a rat brain preparation was determined using bioassay. Hori provided primary evidence for the presence of a kininforming enzyme in rabbit brain (6). This enzyme was only activated by treatment with acid or acetone, acts at neutral $\mathrm{pH}$ on plasma kininogen, and is distributed in the microsomal fraction of the brain. In the present results. however, the kinin-formation was detected only in the acidic $\mathrm{pH}$ ranges, optimally at $\mathrm{pH}$ 3.0, and was exclusively distributed in the crude mitochondrial fraction of the rat brain. Furthermore, in our preliminary experiment, no kinin-forming activity in the present enzyme preparation was detected at neutral $\mathrm{pH}$ even by acid treatment ( $\mathrm{pH} 5.0,2 \mathrm{hr}$ ) as reported by Hori (6). The reason for these distinctions regarding the presence of the neutral kinin-forming enzyme in the brain might depend on different procedures used in the treatments of brains from different species. However, another reason may be the presence of potent kininase activity at the neutral $\mathrm{pH}$ range. In the present preparation, kininase activity measured by bradykinin inactivation was detected over broad $\mathrm{pH}$ ranges, maximally at $\mathrm{pH}$ 6.5-8.5 (data not shown). Therefore, the kinin-forming activity in the neutral range may be masked by the degrading enzyme. In this respect, the kininforming activity detected in the acidic $\mathrm{pH}$ range seems to be unaffected by kininases because in the $\mathrm{pH}$ range below 5.0, kininase activity was hardly detected.

The kinin-forming enzyme of the brain found in this experiment appears to be a cathepsin-D like acid protease because 1) the activity was located exclusively in the crude mitochondrial fraction. which is rich in lysosomes (12), and 2) the activity was potently inhibited by pepstatin, a potent inhibitor of cathepsin-D (17). The CMcellulose column elution profile of the extracted kinin from the reaction mixture was not consistent with those of the authentic bradykinin, Lys-bradykinin, and Met-Lysbradykirin. Moreover, the kinin is about $20-$ fold more potent in decreasing rat blood pressure and about 3 -fold less potent in contracting the guinea pig ileum than bradykinin, in contrast with its action on the rat uterus. Those pharmacological potencies show that the formed kinin in this experiment is not bradykinin. In addition to this evidence. the treatment of kinin with trypsin caused neither increased potential nor decreased the action of kinin on rat uterus. The above results support the idea that the kinin may not contain the peptide sequence of bradykinin, which is unlikely to be Lys-, or Met-Lysbradykinin as shown in Fig. 3. In these points, the enzyme observed in the present experiment seems to be different from splenic acid kininogenases, which are catheptic enzymes and form Met-Lysbradykinin from plasma kininogen (18).

If the kinin is formed in the brain under pathological conditions such as an injury and inflammation, this may play a role in various processes, as in the peripheral tissues (19). For example, in multiple sclerosis, considered one of the most serious neurological diseases, the cathepsin-D-like acid proteases activity is elevated at the edge of active plaques (20), and it has been suggested that the elevated enzyme activity may play an important role in the mechanism of myelin breakdown in this allergic inflammatory dissease (21). The acid protease appears to be identical with the kinin- 
forming enzyme because of its pepstatin susceptibility (22). Therefore, it is considered that the kinin may be produced in lesions and may participate in inflammatory processes.

From the above evidences, it is impressive that the kinin-forming enzyme in the nervous tissue releases the kinin-like peptide from the plasma kininogen fraction. Further experiments are being carried out for elucidating the physiological or pathological significance of the kinin-forming enzyme in the brain.

\section{References}

1 Chang, M.M. and Leeman, E.S.: Isolation of a sialogogic peptide from bovine hypothalamic tissue and its characterization as substance P. J. Biol. Chem. 245, 4784-4790 (1970)

2 Carraway, R. and Leeman, E.S.: The isolation of a new hypotensive peptide, neurotensin, from bovine hypothalami. J. Biol. Chem. 248, 68546861 (1973)

3 Dockray, J.G.: Immunochemical evidence of cholecystokinin-like peptides in brain. Nature 264, 568-570 (1976)

4 Said, S. and Rosenberg, N.R.: Vasoactive intestinal polypeptide: Abundant immunoreactivity in neural cell lines and normal nervous tissue. Science 192, 907-908 (1976)

5 Corréa, M.F., Innis, B.R., Uhl, R.G. and Snyder, H.S.: Bradykinin-like immunoreactive neuronal systems tocalized histochemically in rat brain. Proc. Natl. Acad. Sci. U.S.A. 76, 1489-1493 (1979)

6 Hori, S.: The presence of bradykinin-like peptide, kinin-releasing and destroying activity in brain. Japan. J. Physiol. 18, 772-787 (1968)

7 Shikimi, T., Kema, R., Matsumoto, M., Yamahata, Y. and Miyata, S.: Studies on kinin-like substances in brain. Biochem. Pharmacol. 22, 567573 (1973)

8 Inoue, A., Kataoka, K. and Tsujioka, T.: On a kinin-like substance in the nervous tissue extracts treated with trypsin. Japan. J. Physiol. 11, 319-334 (1961)

9 Oliveira, B.E., Martins, R.A. and Camargo, M.C.A.: Isolation of brain endopeptidases: Influence of size and sequence of substrates structually related to bradykinin. Biochemistry 15, 1967-1974 (1976)

10 Kariya, K., Iwaki, H., Yamauchi, A., Okamoto, M., Tsuda, Y. and Okada, Y.: Central action of bradykinin (II). Separation of bradykinin degrading enzyme from the rat brain. Japan. J.
Pharmacol. 31, 613-619 (1981)

11 Li, C.H., McLimans, F.W. and Back, N.: Purification and characterization of kinin-forming acid protease from mouse fibroblasts L-929. Biochem. Pharmacol. 26, 1187-1195 (1977)

12 Koenig, H., Gaines, D., McDonald, T., Gray, R. and Scott, J.: Brain lysosomes I. Subcellular distribution of five acid hydrolases, succinate dehydrogenase and gangliosides in rat brain. J. Neurochem. 11, 729-743 (1964)

13 Moriwaki, C., Hojima, Y. and Moriya, H.: A proposal-use of combined assays of kallikrein activity measurement. Chem. Pharm. Bull. (Tokyo) 22, 975-983 (1974)

14 Pierce, V.J.: Bradykinin; Purification and biochemical characterization. In Methods in Investigative and Diagnostic Endocrinology, Edited by Berson, A.S. and Yalow. S.R., Vol. 2, 1185-1208, North-Holland Publishing Company. Amsterdam and London (1973)

15 Markwell, K.A.M., Haas, M.S., Bieber, L.L. and Tolbert, E.N.: A modification of the Lowry procedure to simplify protein determination in membrane and lipoprotein samples. Anal. Biochem. 87, 206-210 (1978)

16 Kato, H. and Suzuki, T.: Bradykinin-potentiating peptides from the venom of Agkistrodon hylys blanhoffii. Isolation of five bradykinin potentiators and the amino acid sequences of two of them, potentiators B and C. Biochemistry 10, 972-980 (1971)

17 Woessner, J.F., Jr.: Pepstatin inhibits the digestion of hemoglobin and protein-polysaccharide complex by cathepsin D. Biochem. Biophys. Res. Commun. 47, 965-970 (1972)

18 Yamafuzi, K. and Takeishi, M.: Bovine spleen acid kininogenases. Life Sci. 16, 822 (1975)

19 Zachariae, H., Henningsen, J.S., Sondergaard, $\mathrm{J}$. and Wolf-Jurgensen, P.: Plasma kinins in inflammation-relative to other mediators and leukocytes. Scand. J. Clin. Lab. Invest. 107 Supp., 85-94 (1968)

20 Einstein, R.E., Cseatey, J., Dalal, K., Adams, M.W.C., Bayliss, O.B. and Hallpike, F.J.: Proteolytic activity and basic protein loss in around multiple sclerosis plaques: Combined biochemical and histochemical obsevation. J. Neurochem. 19, 653-662 (1972)

21 Rauch, C.H., Einstein, R.E. and Csejtey, J.: Enzymatic degradation of myelin basis protein in central nervous system lesions of monkeys with experimental allergic encephalomyelitis. Neurobiology 3, 195-205 (1973)

22 Marks, N., Grynbaum, A. and Lajtha, A.: Pentapeptide (Pepstatin) inhibition of brain acid protease. Science 181, 949-950 (1973) 